\title{
Double Trouble: Lown-Ganong-Levine and long QT syndromes
}

D. Guerreiro¹, S. Maurício ${ }^{2}$, J.R. Soares 3 , I. Rodrigues ${ }^{1}$

${ }^{1}$ Centro Hospitalar Lisboa Norte

2 Instituto Português de Oncologia de Lisboa Francisco Gentil

${ }^{3}$ Centro Hospitalar Universitário do Algarve

CENTRO HOSPITALAR LISBOA NORTE, EPE

SANTAMARIA

\section{BACKGROUND}

LOWN-GANONG-LEVINE (LGL) is a rare pre-excitation syndrome associated with an accessory pathway (James bundle) but normal ventricular activation, and supraventricular tachycardias.

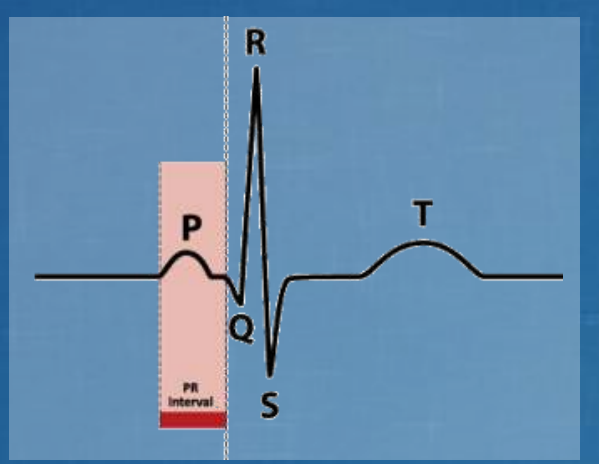

PR interval $<0.12 \mathrm{~s}$

Absence of delta wave

QRS $<0.12$ s with normal morphology

Clinical paroxysmal tachycardia
LONG QT (LQT) is a conduction disorder characterized by prolongation and dispersion of ventricular repolarization, making Torsades de Pointes more likely.

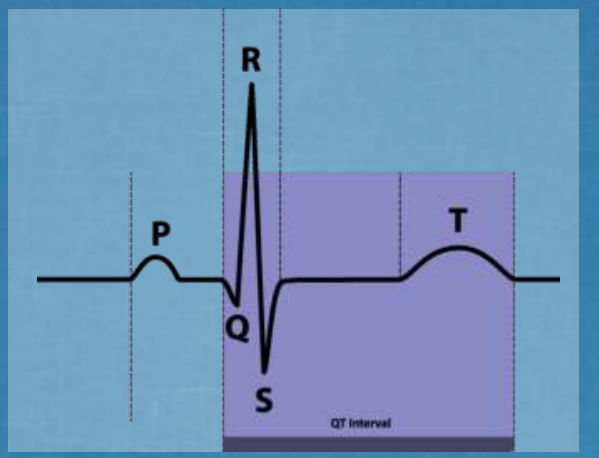

(Bazett formula)

QTc $\geq 0.45 s$

Both syndromes bear a risk of perioperative arrhythmias, with the former potentially increasing the risk of the latter.

Besides antiarrhythmic and common anesthetic drugs might prolong QT.

\section{CASE REPORT}

PRE-OP. EVALUATION

\begin{tabular}{|l|l|}
\hline Procedure & Partial parotidectomy for Warthin tumor \\
\hline $\begin{array}{l}\text { Medical } \\
\text { history }\end{array}$ & $\begin{array}{l}\text { Recurrent palpitations attributed to anxiety } \\
\text { No familial history of sudden death } \\
\text { No medication }\end{array}$ \\
\hline $\begin{array}{l}\text { Physical } \\
\text { examination }\end{array}$ & Normal \\
\hline $\begin{array}{l}\text { ECG } \\
\text { and labs }\end{array}$ & $\begin{array}{l}\text { ECG: SR, 93bpm, PR 0.1s, QRS 0.1s } \\
\text { with normal morphology, QTc 0.46s } \\
\text { Metabolic workup unremarkable }\end{array}$ \\
\hline
\end{tabular}

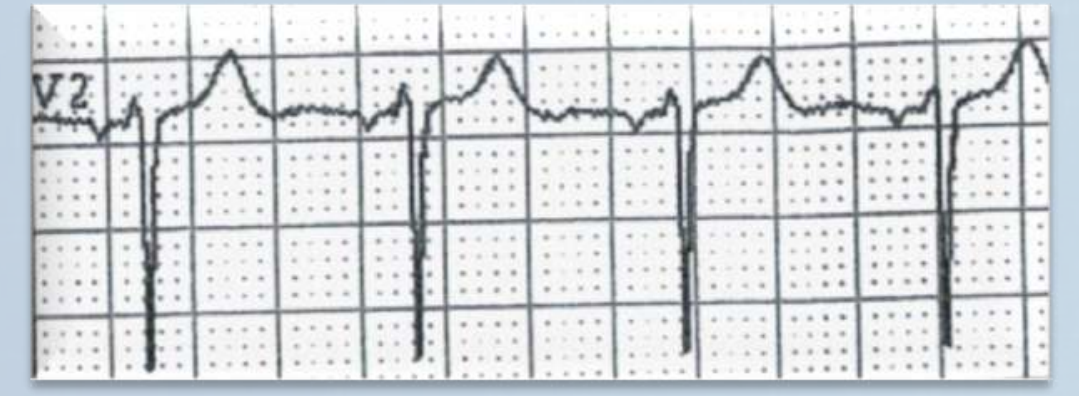

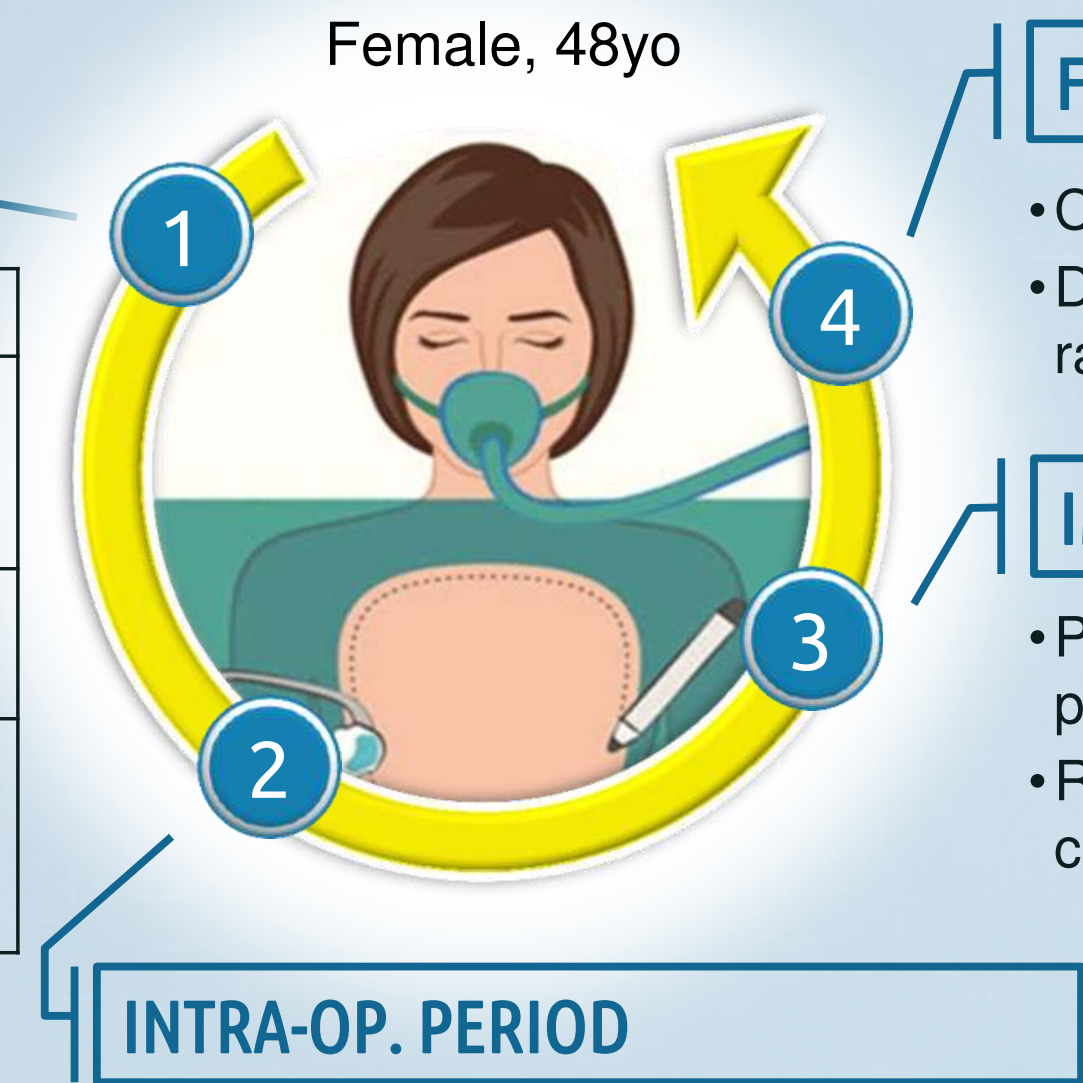

\section{FOLLOW-UP}

- Cardiology referral

- Development of protocols to manage rare but life-threatening arrhythmias

\section{IMMEDIATE POST-OP. PERIOD}

- Post-op. analgesia supplemented with paracetamol $1000 \mathrm{mg} 8 / 8 \mathrm{~h}$

Recover from surgery without complications

Pre-medication: midazolam $1 \mathrm{mg}$

Induction \& maintenance: $\mathrm{TCl}$ of propofol and remifentanil, BIS monitoring PONV prophylaxis: dexamethasone $4 \mathrm{mg}$

Pain management: cervical superficial plexus block, $10 \mathrm{ml}$ ropicavaine $0,75 \%$ No arrhythmias intra-operatively

\section{DISCUSSION}

Despite the scarcity of LGL cases and conflicting data on LQT, some general principles must be followed:

$\checkmark$ beta-blockers maintained

$\checkmark$ magnesium sulphate and external defibrillator available

$\checkmark$ 5-lead ECG, consider A-line

$\checkmark$ adequate anxiolysis, anesthetic depth and analgesia

$\checkmark$ normo -carbia, -temperature, -volemia and electrolytes

$\checkmark$ avoid drugs prolonging QT, although rarely proarrhythmic (droperidol, ondansetron, inhalational agents, etc.)

$\checkmark$ avoid sympathetic stimulation

$\checkmark$ avoid amiodarone when treating tachycardia

\section{LEARNING POINTS}

Appropriate selection of anesthetic drugs and avoidance of arrhythmogenic triggers ensure an uneventful perioperative course.

TIVA is safe in patients with LGL and LQT.

Nerve blocks avoid opioid rescue along with antiemetic drugs known to prolong QT.

REFERENCES

Kies S. Anesthesia for patients with congenital long QT syndrome. Anesthesiology. 2005 Jan;102(1):204-10. Poarid P. Lown-Ganong-Levine syndrome and enhanced atrioventricular nodal conduction. Up ToDate 2017. Sharma M. Anaesthetic management of a patient with Lown Ganong Levine syndrome. MJAFI 2011;67:285-287. Staikou C. Perioperative management of hereditary arrhythmogenic synaromes. Br J Anaesth. 2012 May;108(5):730-44. 